\title{
Multiple bilateral dermoid cysts with ectopic pregnancy: a rare case report
}

\author{
Divya Agrawal*
}

Department of Obstetrics and Gynaecology, Adesh Medical College, Shahbad, Haryana, India

Received: 20 October 2020

Accepted: 01 December 2020

\section{*Correspondence:}

Dr. Divya Agrawal,

E-mail: dr.divyaagrawal82@gmail.com

Copyright: (c) the author(s), publisher and licensee Medip Academy. This is an open-access article distributed under the terms of the Creative Commons Attribution Non-Commercial License, which permits unrestricted non-commercial use, distribution, and reproduction in any medium, provided the original work is properly cited.

\begin{abstract}
Mature cystic teratoma (dermoid) is a common ovarian neoplasm but less frequently occurs bilaterally specially with ectopic pregnancy. It poses challenge in management in a young woman with history of infertility where preservation of ovarian stroma takes the priority. Here presented case of 30-year-old para 0 , gravida 1 women who was diagnosed with ectopic pregnancy with history of infertility of 4 years. She underwent laparotomy where salpingectomy was done owing to tubal rupture. Dermoid cyst was removed simultaneously. When both ovaries were palpated, three more dermoids were found and taken off as well. Earlier ovulation induction was given before adhesions take upper hand and patient was pregnant in first cycle.
\end{abstract}

Keywords: Dermoid cyst, Ectopic pregnancy, Infertility

\section{INTRODUCTION}

Mature cystic teratoma makes about $10-20 \%$ of all ovarian neoplasms and bilateral in nearly 10 to $15 \%$ of all dermoids. ${ }^{1}$ They mainly occur before 40 years of age and most common tumour before 20 years of age.

The term dermoid cyst is a misnomer as it contains derivatives from all three germ layer derivatives i.e ectoderm (skin, hair, brain) mesoderm (muscle, fat, teeth, bone, and cartilage) and endoderm (mucious and ciliated epithelium) and occasionally thyroid tissue (when it is called struma ovary). Malignant transformation occurs unusually (1-3\% of cases) and when occurs usually into a squamous cell cancer. ${ }^{2}$

They are usually asymptomatic or present with nonspecific symptoms. Rarely symptoms related to hormonal secretion such as oestrogen, prolactin, thyroxine may be present.

Ultrasound is the imaging modality of choice. They are characteristically seen as a cystic adnexal mass with mural components. Usually seen as unilocular lesions. On colour doppler no internal vascularity is seen, but if seen, further evaluation is required to rule out malignant transformation.

Dermoids perse doesn't predispose to ectopic pregnancy but when found in association with it, poses dilemma whether should be taken out in same setting.

\section{CASE REPORT}

A patient aged 30 years, para 0 , gravida 1 came to our hospital with complaints of spotting per vaginum for 2-3 days with history of 6 weeks of amenorrhoea and weakly positive pregnancy test at home. There was no history of pain in abdomen, dysuria, or dyschesia.

She was married for 4 years with history of infertility and taking treatment for infertility on and off.

She was vitally stable otherwise. On examination, abdomen was soft and non-tender. On per speculum examination, fresh bleeding was seen coming through cervical os and vaginal examination revealed right forniceal tenderness and cervical motion tenderness. 
She was investigated with urgent ultrasound examination of pelvis which showed right tubal ectopic pregnancy (stated as -a well-defined gestational sac is seen outside the uterine cavity on right side with CRL corresponding to 8 weeks of gestation and cardiac activity absent. Another well-defined round echogenic lesion of size $4 \times 4.4 \times 2.8 \mathrm{~cm}$ is seen on right side suggestive of likely dermoid) with likely dermoid on same side. Blood investigations were normal with $\beta \mathrm{HCG}$ of $24040 \mathrm{mIU}$.

Patient was consented for laparotomy as she refused for laparoscopy.

\section{Per operative findings}

Ampullary right tubal ectopic with rupture for which right salpingectomy was done. Bilateral ovaries showed four dermoids in total ( 2 in each ovary) which were removed with ovarian reconstruction (Figure 1). Left sided fallopian tube was normal. Cut section of the gross specimen of the dermoids revealed plenty of sebaceous fluid with large tuft of hair. No spillage of contents happened during operation.

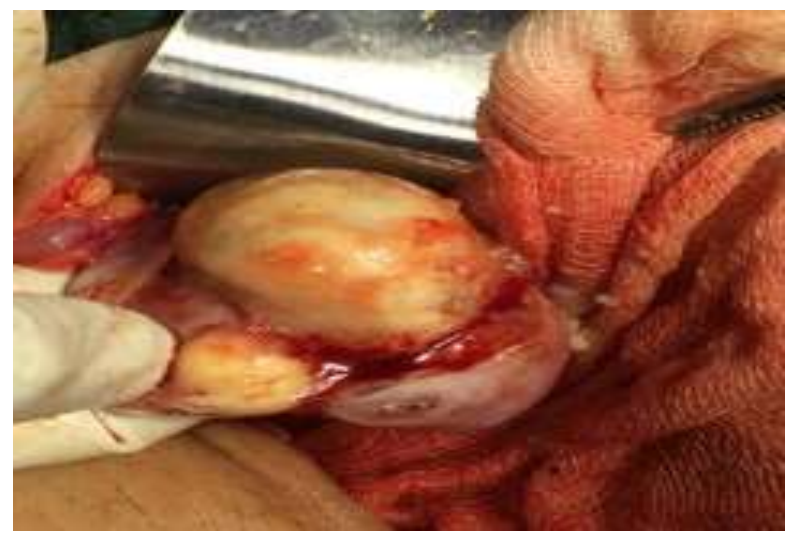

Figure 1: Intra operative picture showing 2 dermoid cysts being removed from right ovary.

Patient was discharged on 7th day with complete resolution of symptoms and followed in OPD after 3months for infertility treatment. Histopathology confirmed lesions as dermoids.

\section{Infertility management}

Hormonal studies conducted on 2nd day of periods (LH: 2.6 IU/L, FSH: 7.9IU/L, TSH: 1.63, testosterone: 26.48 $\mathrm{ng} / \mathrm{dl})$

\section{Semen analysis normal}

Ovulation induction given, which led to development of 2 mature follicles. HCG was not given in first cycle and patient advised for regular intercourse. Patient conceived in first cycle itself, pregnancy went normal with full term cesarean section done for breech.
Informed consent was obtained from the patient prior inclusion of details in this case report.

\section{DISCUSSION}

This case is particularly interesting as bilateral teratoma is rare condition and even rarer when it occurs with ectopic pregnancy (only 2 cases are reported till date). At the same time management of this case is challenging as patient has history of infertility where preservation of ovarian stroma is required as well as consideration of pelvic adhesions post operatively is to be kept in mind.

The case report highlights that there can be multiple dermoids and thus signifies the importance of tactile evaluation of both ovaries if one ovary contains the same. In young patients where fertility and cosmesis are both desired outcomes, laparoscopy is the first line of treatment with specific attention towards prevention of spillage of contents. ${ }^{3}$ Here in this case, laparoscopy would not have identified those small dermoids but at the same time how much was it important to take out those small fibroids is still a dilemma.

Sutures may be better for homeostasis as compared to electro diathermy as ovarian follicles are sensitive to thermal energy. ${ }^{4}$ Rupture of dermoid both during laparoscopy and laparotomy is a known complication with rates during laparoscopy (15-100\%) and laparotomy (4-13\%). Shock and haemorrhage among the immediate complications and adhesion formation being the late one. Though recurrence can be there, undiagnosed small dermoid cysts may be one of the reasons.

If we focus on complications of dermoid, ovarian torsion is most common (3-16\%). Rupture in (1-4\%), malignant transformation (1-2\%). Among rare ones are infection, hyperthyroidism and carcinoid syndrome.

Dermoids are generally slow growing tumours with growth rate of 1-2 mm/year. ${ }^{5}$ Radiologically there are varied appearances described. Most common is Rokitansky nodule (also known as solid protuberance often containing hair, dental, adipose or calcific components) also known as 'dermoid plug' is seen in around $80 \%$ of cases. ${ }^{5}$ Other less common radiological features such as 'dot dash sign': (hyper echoic lines and dots arising from hairs in different planes), floating ball sign: (floating hyper echoic globules moving with changing position of patient), Comet tail appearance may be seen., MRI may be required for diagnosis where features are atypical on ultrasound.

\section{CONCLUSION}

I emphasize on benefit of tactile evaluation of ovary and complete removal of small dermoids not detected on ultrasound where feasible i.e. when laparotomy is considered for any reason in best interest of patient. Also, if fertility is an issue, early ovulation induction should be 
considered before adhesions pose speed breaker in our journey.

Funding: No funding sources

Conflict of interest: None declared

Ethical approval: Not required

\section{REFERENCES}

1. Rha SE, Byun JY, Jung SE, Kim HL, Oh SN, Kim $\mathrm{H}$, et al. Atypical CT and MRI manifestations of mature ovarian cystic teratomas. AJR Am J Roentgenol. 2004;183(3):743-50.

2. Comerci JT Jr, Licciardi F, Bergh PA, Gregori C, Breen JL. Mature cystic teratoma: a clinicopathologic evaluation of 517 cases and review of the literature. Obstet Gynecol. 1994;84(1):22-8.

3. Kaminski P, Gajewska M, Wielgos M, Szymusik I. Laparoscopic management of dermoid cysts in patients of reproductive age. Neuro Endocrinol Lett. 2006;27(6):818-21.
4. Pergialiotis V, Prodromidou A, Frountzas M, Bitos K, Perrea D, Doumouchtsis SK. The effect of bipolar electrocoagulation during ovarian cystectomy on ovarian reserve: a systematic review. Am J Obstet Gynecol. 2015;213(5):620-8.

5. Caspi B, Appelman Z, Rabinerson D, Zalel Y, Tulandi T, Shoham Z. The growth pattern of ovarian dermoid cysts: a prospective study in premenopausal and postmenopausal women. Fertil Steril. 1997;68(3):501-5.

6. Sahin H, Abdullazade S, Sanci M. Mature cystic teratoma of the ovary: a cutting-edge overview on imaging features. Insights Imaging. 2017;8(2):22741.

7. Williams PL, Dubbins PA, Defriend DE. Ultrasound in the diagnosis of ovarian dermoid cysts: a pictorial review of the characteristic sonographic signs. Ultrasound. 2011;19(2):85-90.

Cite this article as: Agrawal D. Multiple bilateral dermoid cysts with ectopic pregnancy: a rare case report. Int J Reprod Contracept Obstet Gynecol 2021;10:358-60. 